Artigo

\title{
Análise de um Vórtice Ciclônico e Mesoescala Associado a ZCAS em Janeiro de 2009
}

\author{
Mário Francisco Leal de Quadro ${ }^{1}$, Maria Assunção Faus da Silva Dias ${ }^{2}$, Dirceu Luis Herdies ${ }^{3}$ \\ ${ }^{1}$ Instituto Federal de Santa Catarina, Florianópolis, SC, Brasil. \\ ${ }^{2}$ Instituto de Astronomia e Geofisica, Universidade de São Paulo, São Paulo, SP, Brasil. \\ ${ }^{3}$ Centro de Previsão de Tempo e Estudos Climáticos, Instituto Nacional de Pesquisas Espaciais, \\ Cachoeira Paulista, SP, Brasil.
}

Recebido: 29/11/2015 - Aceito: 13/05/2016

\begin{abstract}
Resumo
Este trabalho objetiva analisar a condição termodinâmica durante a atuação de um vórtice ciclônico de mesoescala (VCM) embebido na Zona de Convergência do Atlântico Sul (ZCAS), no mês de janeiro de 2009. Os VCMs possuem características similares: encontram-se na baixa e média troposfera associado a altos índices pluviométricos, ciclo de vida inferior a $24 \mathrm{~h}$, escala espacial de aproximadamente $200 \mathrm{~km}^{2}$ e o descolamento do sistema na mesma direção do fluxo predominante na baixa troposfera. Além disso, há uma relação direta entre estes máximos pluviométricos e a circulação ciclônica dos vórtices. O VCM simulado através do modelo de mesoescala BRAMS se formou no Estado de Mato Grosso e esteve associada à ocorrência de chuvas intensas. Além das características típicas de caracterização, este sistema também apresentou vorticidade relativa da mesma ordem de magnitude do parâmetro de Coriolis $\left(10^{-4} \mathrm{~s}^{-1}\right)$, núcleo quente acima do nível de máxima intensidade e um rápido crescimento do centro de vorticidade ciclônica principalmente nos baixos níveis. Pela comparação da chuva simulada com o produto Hidroestimador, sugere-se que o modelo BRAMS, com uma alta resolução espacial e temporal, melhora a representação do VCM, comparado com os dados da reanálise CFSR do NCEP.
\end{abstract}

Palavras-chave: vórtice ciclônico de mesoescala, ZCAS, precipitação.

\section{Analysis of a Mesoscale Cyclonic Vortex Associated with SACZ During January 2009}

\begin{abstract}
This study shows, from the mesoscale analysis perspective that Mesoscale Cyclonic Vortex (MCV) is associated to the South Atlantic Convergence Zone (SACZ) through a feedback process. This system, simulated by the BRAMS regional model, is generated embedded in a stratiform environment within the SACZ region, during the January 2009 austral summer. MCVs present similar characteristics which could be considered as a "signature" for such systems. The case study also presents a lifetime shorter than $24 \mathrm{~h}$ and spatial scale of approximately $200 \mathrm{~km}^{2}$ in addition to intense precipitation, shifting in the flow direction in the lower troposphere. In the case occurred in the Mato Grosso State, the presence of this system was associated with heavy rain, relative vorticity of the same order as the Coriolis parameter $\left(10^{-4} \mathrm{~s}^{-1}\right)$, warm core above the level of maximum intensity and rapid growth of the cyclonic vorticity center mostly in the lower levels. The simulated precipitation is compared against the Hidroestimador precipitation product. The results suggest that the BRAMS model, configured with high spatial and temporal resolutions improves the representation of the MCVs when compared to the NCEP CFSR reanalysis.
\end{abstract}

Keywords: mesoscale cyclonic vortex, SACZ, precipitation. 


\section{Introdução}

A Zona de Convergência do Atlântico Sul (ZCAS) é um fenômeno meteorológico que exerce um papel preponderante no regime de chuvas na região onde atua, acarretando altos índices pluviométricos na América do Sul (Ferreira et al., 2004; Grimm, 2011). Este estudo mostra que, em uma análise de mesoescala, um Vórtice Ciclônico de Mesoescala (VCM) (Johnston, 1982; Brandes and Ziegler 1993) está associado à ZCAS através de um processo de retroalimentação. Este sistema é gerado dentro de um ambiente estratiforme na região da ZCAS, suga a umidade, acelera os ventos na vertical provocando intensa precipitação e, como conseqüência, pode afetar drasticamente as regiões atingidas provocando sérios danos socioeconômicos.

\subsection{Características de um vórtice convectivo de mesoescala}

Vários estudos têm mostrado que a precipitação estratiforme pode ter um importante impacto na formação e/ou intensificação dos mesovórtices (Houze, 1977; Bartels and Maddox 1991; Brandes and Ziegler 1993, entre outros). Tais sistemas se formam tanto nos trópicos como em latitudes médias e são caracterizados pela significativa concentração de vorticidade relativa ciclônica na baixa e média troposfera, com ordem de magnitude próxima ao parâmetro de Coriolis. Johnston (1982), através de análise de imagens de satélite, mostrou que tais vórtices desenvolvem-se muito comumente durante os estágios maduro e de decaimento dos Sistemas Convectivos de Mesoescala (SCMs) e podem contribuir com o desenvolvimento da convecção subseqüente (Bartels e Madox, 1991). Bosart e Sanders (1981), por sua vez, notaram o surgimento de movimento ascendente na média troposfera durante o estágio maduro de um Complexo Convectivo de Mesoescala (CCM). Este movimento ascendente está altamente correlacionado com circulação ciclônica nos médios níveis e anticiclônica na alta troposfera. Os vórtices convectivos de mesoescala têm diâmetro de 50 a $300 \mathrm{~km}$ e desenvolvem-se embebidos as correntes ascendentes ou descendentes de mesoescala (Brandes and Ziegler, 1993).

Um mesovórtice na porção estratiforme de um SCM é caracterizado por ter um núcleo quente, onde o ar quente ascendente induz a convergência nos níveis médios da troposfera e posteriormente contribui para a amplificação da vorticidade ciclônica. No ramo subsidente o sistema é denominado como um vórtice induzido por resfriamento, pois está associado com entrada de ar frio nas correntes descendentes na retaguarda do sistema, o que ajuda a concentrar vorticidade ciclônica, sendo que os efeitos de resfriamento são devido à sublimação, fusão, evaporação e derretimento (Johnson e Bartels, 1992; Brandes e Ziegler, 1993). A Fig. 1 ilustra um exemplo da formação de um mesovórtice nas regiões estratiforme (porção ascendente) e convectiva (ramo associado às correntes descendentes) de
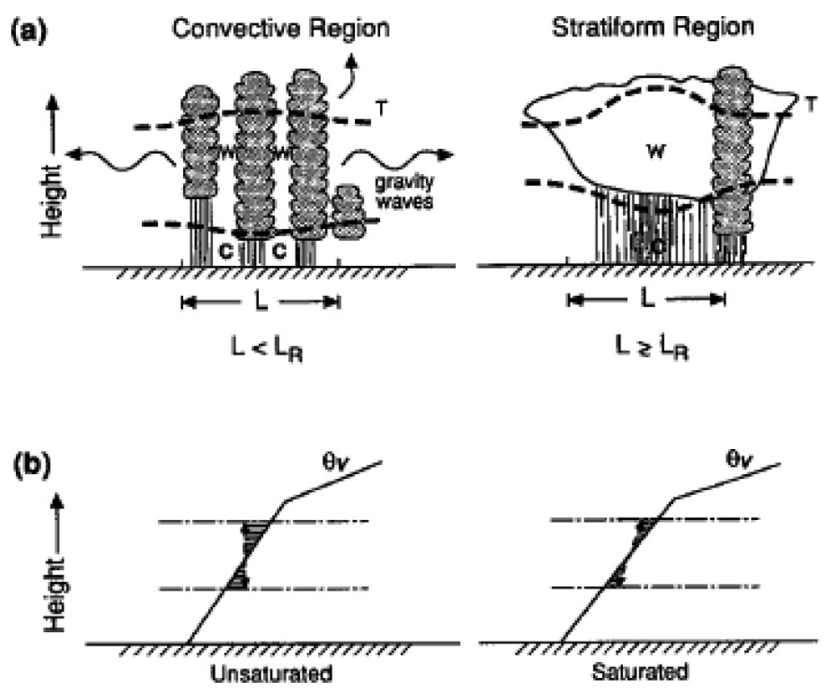

Figura 1 - Diagrama esquemático de (a) uma região convectiva e outra estratiforme (linhas tracejadas representam as anomalias de temperatura) e (b) trajetórias da parcela de ar (região sombreada) e lapse rate vertical da temperatura potencial virtual $\left(\theta_{v}\right)$ nas duas regiões. Extraída de Chen e Frank (1993).

um SCM. Fisicamente, a resposta atmosférica a uma fonte local de calor depende da escala horizontal dessa fonte de calor $(\mathrm{L})$ e do raio de deformação de Rossby $\left(\mathrm{L}_{\mathrm{R}}\right)$. Em uma região não saturada dentro de um SCM são tipicamente observados aglomerados de nuvens em forma de torres (torres de cumulus) no estágio inicial de seu ciclo de vida (Houze et al., 1989), onde o aquecimento produzido devido à liberação do calor latente na convecção profunda é muito pequeno (Fig. 1a). Por outro lado, na região estratiforme saturada do SCM, com a mesma escala espacial da região convectiva, $L_{R}$ pode ser reduzido a um valor igual ou menor que L devido à redução da estabilidade na região saturada. Portanto, considerando a integração nas duas áreas, o calor produzido em uma região estratiforme pode ser muito mais intenso do que em uma região convectiva do SCM. Em função disso, um mesovórtice que se forma na porção estratiforme de um SCM é caracterizado por ter um núcleo quente, onde o ar quente ascendente induz a convergência nos níveis médios da troposfera e posteriormente contribui para a amplificação da vorticidade ciclônica.

Com relação ao ciclo de vida dos vórtices convectivos de mesoescala, James e Johnson (2010) concluem que parece haver nenhuma relação significativa entre a longevidade e a intensidade dos mesovórtices. Estes sistemas geralmente se configuram no início da manhã (associado ao ciclo diurno da convecção), perto da hora do limite máximo de intensificação dos SCM e sua dissipação está associada ao enfraquecimento/deslocamento de um cavado de mesoescala persistente na média troposfera. Com o objetivo de mostrar as características de um vórtice de mesoescala de núcleo quente, Zhang e Fritsch (1987) analisaram através de uma simulação numérica a formação deste sistema, associado com um CCM que provocou uma enchente na 
cidade de Johnstown (EUA) em 1977. Este vórtice apresentou máximo de vorticidade ciclônica entre 850 e $700 \mathrm{hPa}$, teve uma duração de aproximadamente $18 \mathrm{~h}$ e sua escala espacial abrangia de 100 a $200 \mathrm{~km}$ de diâmetro. Entre a superfície e $850 \mathrm{hPa}$ desenvolveu-se uma piscina fria e úmida associada as correntes de ar subsidente, enquanto que na vizinhança da tropopausa formou-se um domo frio acima do núcleo quente. Além disso, uma intensa circulação ciclônica estendeu-se até $300 \mathrm{hPa}$, a partir do qual tornou-se anticiclônica. Nos altos níveis formou-se uma mesoalta que atuou como um obstáculo, forçando o vento horizontal a contorná-la e desenvolvendo uma corrente de jato a noroeste, entre a circulação anticiclônica e a zona baroclínica ao norte. A gênese do mesovórtice ocorreu em um ambiente quase saturado, ligeiramente condicionalmente instável com fraca deformação horizontal e cisalhamento vertical. Este sistema é energeticamente suportado inicialmente pela liberação de calor latente de condensação nas nuvens na escala da grade desde a baixa até a média troposfera. Sua evolução depende do desenvolvimento da conveção profunda assim como da estrutura do fluxo de mesoescala. Nesse caso, as correntes descentes úmidas tiveram um papel importante tanto na intensificação do vórtice como nos totais pluviométricos. Por fim, no estágio de dissipação o vórtice é mantido devido a estabilidade inercial. Quadro (2012) mostra mais detalhes sobre os princípios físicos para formação de um VCM em um ambiente estratiforme de um SCM.

\subsection{Estudos de casos de VCM na BFZ}

Atualmente, pode-se afirmar que a previsibilidade da ZCAS pelos atuais modelos operacionais regionais (e até em escala global) é bastante limitada, provavelmente pelo fato de que estes modelos ainda não são capazes de reproduzir adequadamente os perfis de aquecimento associado ao sistema. Além disso, os esquemas de análise e assimilação de dados não são suficientemente precisos para reproduzir adequadamente a estrutura em mesoescala da ZCAS. No caso da Baiu Frontal Zone (BFZ), que se forma na região do Japão, onde há vários estudos relacionando essas estruturas à topografia, contraste terra-mar e formação de vórtices. Chen et al. (1998) mostraram que os sucessivos desenvolvimentos desses sistemas, propagando-se para leste, provocaram máximos de precipitação superiores a 230 mm acumulados em 24 h. Simulações numéricas sugeriram que há uma forte interação entre a BFZ e o sistema convectivo embebido, através de um processo de realimentação positivo. A zona de convergência fornece as condições atmosféricas favoráveis ao desenvolvimento da tempestade, que por sua vez intensifica a BFZ. Um experimento adicional mostrou que a liberação de calor latente é crucial para o desenvolvimento da tempestade, o jato de baixos níveis, a mesobaixa associada e a consequente manutenção da zona de convergência.
Chen et al. (2000), analisaram a estrutura tridimensional da sucessiva formação dos dois sistemas convectivos de mesoescala (SCM) ao longo da BFZ. A evolução desses sistemas foi associada à presença dos jatos de baixos níveis de mesosescala (JBNm) e de altos níves de mesosescala (JANm), respectivamente, ao sul e a leste dos sistemas convectivos. As análises indicam que ambos os jatos formaram-se em resposta a intensa atividade convectiva associada aos SCM. Uma simulação inibindo a liberação de calor latente ainda mostrou a presença dos movimentos ascendentes, associados aos VCM. Esse resultado sugere que a formação inicial dos SCM pode se dar na ausência dos processos adiabáticos úmidos, desde que os gradientes de velocidade do vento e de temperatura, ao longo da zona de convergência, sejam relativamente fortes e fracos, respectivamente.

Ninomiya (2007) analisa tanto para a BFZ como para a ZCAS as características de grande escala e de escala meso- $\alpha$, assim como a relação dessas características com os demais sistemas sinóticos atuantes. A ZCAS é caracterizada como o limite polar da massa de ar tropical úmida com grande gradiente de umidade, com uma camada interior de umidade e uma zona baroclínica. Neste trabalho, o autor ainda salienta que: (a) as influências de distúrbios tropicais e sistemas convectivos na ZCAS são fracos, ao contrário do que ocorre com a BFZ; (b) a ZCAS é mais baroclínica do que a BFZ e (c) o aparecimento de distúrbios tropicais e sistemas convectivos ativos não é freqüente sobre o Atlântico Sul. É importante ressaltar aqui que o trabalho de Ninomiya (2007) descreve somente a região oceânica da ZCAS e não a região continental. Neste artigo pretende-se avaliar justamente o impacto dos sistemas convectivos embebidos ao longo da banda de nebulosidade da ZCAS.

Em função do exposto, o objetivo central desse estudo é de simular através de modelagem numérica a o ciclo de vida de um mesovórtice gerado dentro de um ambiente estratiforme na região da ZCAS. As simulações descritas abaixo visam analisar os processos físicos, assim como as condições de grande escala, que favorecem a formação dos mesovórtices. Em uma próxima etapa é feita uma avaliação entre os resultados do modelo e os dados da reanálise $\mathrm{Cli}$ mate Forecast System Reanalysis (CFSR) (Saha et al., 2010) do National Centers for Environmental PredictionNational Center for Atmospheric Research (NCEP). Finalmente são analisadas as propriedades termodinâmicas destes vórtices, identificados nos períodos selecionados de ZCAS.

\section{Dados e Metodologia}

Visando avaliar os mecanismos termodinâmicos que disparam a formação e a atuação dos mesovórtices embebidos na região da ZCAS, realizou-se uma simulação numérica com o modelo BRAMS (versão 4.2) (Freitas et al., 
2007), rodado atualmente junto a Divisão de Modelagem e Desenvolvimento (DMD) do Centro de Previsão de Tempo e Estudos Climáticos do Instituto Nacional de Pesquisas Espaciais (INPE/CPTEC). Este modelo foi selecionado, pois tem sido utilizado para estudos das características da ZCAS do ponto de vista da modelagem numérica. Recentemente Nóbile Tomaziello (2010), analisando as influências da temperatura da superfície do mar (TSM) e da umidade do solo na precipitação associada à zona de convergência, mostrou que o modelo apresenta alto desempenho na detecção da quantidade da precipitação principalmente em situações onde o solo se encontrava mais seco e a precipitação foi devida a convergência de umidade oriunda de áreas circunvizinhas.

O VCM foi selecionado embebido na banda de nebulosidade da ZCAS, que se formou entre os dias 22 e 25/11/2009, com base em um sistema objetivo de detecção da formação do respectivo vórtice ciclônico. O trabalho de Quadro (2012) descreve o critério de seleção, que é baseado em: (i) Mínimo de vorticidade relativa $(\zeta)$, em relação aos pontos de grade ao redor, no determinado nível de pressão na região da banda de nebulosidade associada à ZCAS; (ii) Circulação do vento no sentido horário em torno do ponto central de mínimo de $\zeta$ e (iii) Valor médio da variável cobertura de nuvens acima de $90 \%$, para indicar a presença de nebulosidade na região de formação do vórtice.

A simulação numérica realizada do episódio de ZCAS é feita utilizando-se a reanálise do NCEP CFSR como condição inicial e de contorno. Nessa simulação é utilizada uma grade de $5 \mathrm{~km}$ de espaçamento para analisar as características específicas do sistema. A tabela 1 mostra as principais características das simulações. No anexo A são apresentadas as configurações do modelo para uma das simulações efetuadas neste estudo (RAMSIN).

Nesse trabalho também se analisa o balanço de vorticidade na região central do vórtice que revela as diferentes contribuições dos processos que contribuem para o crescimento e o desenvolvimento do mesovórtice. A taxa de variação da vorticidade relativa pode ser escrita em coordenada-z como na Eq. (1).

$$
\frac{\partial \zeta}{\partial t}=H+V+D+T+S+F
$$

onde $H=-\vec{V} \cdot \nabla(\zeta+f)$ é contribuição da variação da vorticidade relativa devido a advecção horizontal de vorticidade absoluta, $V=-w(\partial \zeta / \partial z)$ é a variação devido a

Tabela 1 - Principais opções utilizadas para a simulação no modelo BRAMS.

\begin{tabular}{|c|c|}
\hline Opções da Simulação & Informações \\
\hline Período de Simulação & $00 \mathrm{Z}$ de $22 / 01 / 2009$ a $00 \mathrm{Z}$ de $25 / 01 / 2009$ \\
\hline Número de pontos de grade em $\mathrm{x}$ & 600 \\
\hline Longitude Central & $58^{\circ} \mathrm{W}$ \\
\hline Número de pontos de grade em y & 600 \\
\hline Latitude Central & $15^{\circ} \mathrm{S}$ \\
\hline Número de níveis na vertical & 36 \\
\hline Altura do primeiro nível (DELTAZ) na vertical (m) & 80 \\
\hline $\begin{array}{l}\text { Razão de acréscimo de DELTAZ entre superfícies adjacentes nos baixos níveis } \\
\text { (DZRAT) }\end{array}$ & 1.2 \\
\hline Limite superior sobre espaçamento de grade vertical em função de DZRAT & 1000 \\
\hline Altura do Topo do modelo (m) & 25236 \\
\hline Tempo de nudging lateral (s) & 900 \\
\hline Tempo de nudging central (s) & 0 \\
\hline Tempo de nudging no topo (s) & 10800 \\
\hline Espaçamento dos pontos de grade $(\mathrm{km})$ & 5 \\
\hline Inicialização da umidade do solo & Heterogênea $(0.30,0.30,0.30,0.25,0.25,0.20,0.20,0.18,0.15)$ \\
\hline Tipo de solo & Arquivo de dados USGS (United States Geological Survey) \\
\hline Número de camadas de solo & 9 \\
\hline Profundidade das camadas do solo $(\mathrm{cm})$ & $5,25,50,75,100,125,150,175,200$ \\
\hline Parametrização de radiação & CARMA (Toon et al, 1989) \\
\hline Parametrização convectiva & Desligada \\
\hline Nível de microfísica & 3 (Walko et al.., 1995) \\
\hline Parametrização de Turbulência & Mellor e Yamada (1982) \\
\hline Atualização dos dados NDVI & Ligada \\
\hline
\end{tabular}


advecção vertical, $D=-(\zeta+f) \nabla \cdot \vec{V}$ é a variação devido ao estiramento (streatching) (divergência ou convergência), $T=\vec{k} \cdot\left[\frac{\partial \vec{V}}{\partial z} \times \nabla w\right]=-\left(\frac{\partial w}{\partial x} \frac{\partial v}{\partial z}-\frac{\partial w}{\partial y} \frac{\partial u}{\partial z}\right)$ é parte da variação devido a torção (twisting) do componente horizontal da vorticidade, $S=-\vec{k} \cdot(\nabla \alpha \times \nabla p)=-\left(\frac{\partial \alpha}{\partial x} \frac{\partial p}{\partial y}-\frac{\partial \alpha}{\partial y} \frac{\partial p}{\partial x}\right)$ é a variação na vorticidade devido ao termo solenoidal e $F$ é o termo de resíduo, devido aos efeitos do atrito, efeitos subgrade, convecção não resolvida, transportes turbulentos, entre outros, não mostrado aqui neste trabalho. $\mathrm{Na} \mathrm{Eq.} \mathrm{(6),}$ $\zeta$ é a vorticidade relativa, $f$ é o parâmetro de Coriolis, $\vec{V}$ é a velocidade horizontal, $\alpha=1 / \rho$ é o volume específico do ar (inverso da densidade do ar), $w$ é a velocidade vertical em coordenadas cartesianas, $\vec{k}$ é o vetor unitário na direção vertical e $\nabla$ o operador gradiente horizontal. Como as saídas pós-processadas do modelo são geradas a cada hora, no resultado final é calculado o campo médio de cada termo do balanço entre dois intervalos de tempo consecutivos.

Finalmente, visando avaliar os resultados do modelo, em termos de localização e intensidade de precipitação associada ao sistema, os resultados são comparados com os dados da reanálise CFSR do NCEP e com dados de precipitação derivados do produto Hidroestimator (Scofield, 2001). O Hidroestimator foi inicialmente desenvolvido por Vicente et al. (1998) junto ao NESDIS (National Environmental Satellite, Data, and Information Service) é um algoritmo que produz estimativas instantâneas de precipitação de modo automático a cada 15 minutos, fazendo o uso de imagens infravermelhas do satélite GOES. Este algoritmo calcula a taxa de precipitação inicial utilizando-se de um ajuste de potência entre estimativas instantâneas de precipitação derivadas de radares meteorológicos (quando disponíveis) e medidas de temperatura de brilho do satélite, além de considerar fatores adicionais como o regime de umidade, crescimento e estrutura do topo de nuvens. Esta técnica parte da suposição que nuvens que possuem temperatura do topo mais fria proporcionam maiores taxas de precipitação que aquelas com temperatura do topo mais quente.

\section{Resultados}

Entre os dias 22 e 25 de janeiro de 2009 foi realizada uma simulação numérica através do modelo BRAMS para simular o comportamento da ZCAS e dos VCM associados. No período de $21 Z$ do dia 23 e $15 Z$ de 24 de janeiro foi possível observar o ciclo de formação de um mesovórtice no Estado de Mato Grosso (MT), na região da ZCAS Continental Amazônica (ZCA). Sobre essa região, o modelo mostra algumas características marcantes da presença da ZCAS, como o transporte de umidade e calor nos baixos níveis, que contribuem para a formação do mesovórtice. Em função disso, algumas características importantes para a caracterização desse sistema podem ser salientadas. $O$ VCM apresenta: (a) um deslocamento para sul, seguindo o escoamento em baixos níveis com os maiores índices pluviométricos localizados a sudeste do centro do sistema de mesoescala; (b) escala espacial de aproximadamente $200 \mathrm{x}$ $200 \mathrm{~km}^{2}$ ( $2^{\circ}$ de latitude/longitude); (c) $\zeta$ é da mesma ordem de magnitude de $f\left(10^{-4} \mathrm{~s}^{-1}\right)$; (d) núcleo quente (frio) acima (abaixo) do nível de máxima intensidade e (e) ciclo de vida inferior a $24 \mathrm{~h}$.

A Fig. 2 mostra a imagem realçada do canal infravermelho do satélite meteorológico GOES-10 (Fig. 2a) e os resultados da simulação do modelo BRAMS que caracterizam os estágios do ciclo de vida do vórtice de mesoescala. Pela imagem do satélite é possível observar no final da tarde do dia 23 de janeiro a presença de atividade convectiva ao longo da ZCAS. A simulação indica que esta atividade esteve associada a um jato de baixos níveis de noroeste em $2313.1 \mathrm{~m}$, que transporta umidade a partir da região amazônica para a região de interesse (Fig. 2b). Por esta figura se observa predomino de vento de sul/sudoeste (norte/nordeste) a oeste (leste) da região de formação do mesovórtice. Este cisalhamento horizontal configura uma circulação ciclônica centrada em aproximadamente em $12^{\circ} \mathrm{S} / 55^{\circ} \mathrm{W}$. Essa região é caracterizada pela presença de vorticidade ciclônica e condições de estabilidade, com valores de CAPE menores que 100 (figuras não mostradas). Outra característica dessa região é a ocorrência de precipitação fraca na região central, com núcleos mais intensos (tons verdes na Fig. 2b) associados a intensas áreas de convecção profunda concentrada próxima das bordas leste e oeste do sistema.

No estágio de intensificação do VCM, verifica-se a presença de sistemas convectivos maiores e mais organizados (Fig. 2c). Nesse período (madrugada do dia 24 de janeiro) a simulação indica o VCM bem organizado e com seu centro localizado mais ao sul em relação ao estágio de formação (Fig. 2d). Nesse horário a ZCAS continua contribuindo com fornecimento de umidade para o sistema através do seu escoamento em baixos níveis. $\mathrm{Na}$ região dianteira do sistema algumas nuvens convectivas espalhadas apresentam-se embebidas nas nuvens estratiformes da ZCAS. Na manhã do dia 24 a imagem do satélite GOES-10 já mostra um sistema convectivo intenso na parte sudeste do Estado de MT (Fig. 2e), enquanto que o modelo simula o vórtice com seu centro a noroeste deste sistema (Fig. 2f). Ressalta-se que as áreas com precipitação mais intensa coincidem com a localização do sistema convectivo na imagem de satélite. Finalmente, no estágio de dissipação o mesovórtice encontra-se na sua posição mais meridional, com a banda de precipitação mais intensa organizada em forma de gancho a sudeste do centro do sistema (Fig. 2h).

A Fig. 3 mostra a série temporal obtida na simulação numérica do perfil vertical de vorticidade relativa e da anomalia de temperatura em relação à média zonal, no centro do VCM, durante os estágios de seu ciclo de vida. A 
Fig. 3a mostra claramente o rápido crescimento do centro de vorticidade ciclônica nos baixos níveis (aproximadamente $2 \mathrm{~km}$ de altura) atingindo sua máxima intensidade 6 $\mathrm{h}$ após sua formação ( $03 \mathrm{Z}$ de 24 de janeiro), e reduzindo sua intensidade até as $12 \mathrm{Z}$ do mesmo dia. Outra característica desse sistema é o predomínio de vorticidade ciclônica em praticamente todos os níveis da troposfera, seguido de uma inversão na sua rotação (vorticidade anticiclônica) acima de $14 \mathrm{~km}$ de altitude. Assim como nos casos selecionados através da reanálise CFSR do NCEP, a estrutura térmica destes vórtices concorda com a dos vórtices encontrados no trabalho de James e Johnson (2010), que mostra um núcleo frio abaixo do máximo de vorticidade e uma taxa de aquecimento em direção à média e alta troposfera (Fig. 3b). Note que esse aquecimento de até $3{ }^{\circ} \mathrm{C}$ no período da noite e madrugada, dentro da região estratiforme da ZCAS é devido à condensação e o resfriamento anômalo de até $4{ }^{\circ} \mathrm{C}$ próximo a superfície é devido à evaporação e ao derretimento da precipitação. Além disso, é importante ressaltar que tanto o aquecimento anômalo acima do nível de formação do vórtice e do resfriamento anômalo abaixo contribui para a redução da pressão em direção a média troposfera.

A seção vertical ao longo da linha $\mathrm{AB}$ apresentada na Fig. 2b é mostrada na Fig. 4. Observa-se que no estágio de formação do vórtice o predomínio de movimento vertical (w) ascendente na coluna, entre as longitudes de $56.5^{\circ} \mathrm{W}$ e $54.5^{\circ} \mathrm{W}$, com máximos de w nas extremidades do sistema associados a picos máximos de precipitação (Fig. 4a), e entre $2 \mathrm{~km}$ e $7 \mathrm{~km}$ de altitude. Especificamente na borda oeste do VCM, esta região pode ser caracterizada pela forte corrente ascendente de mesoescala está associada à convecção profunda acima do nível de formação do mesovórtice e ar subsidente abaixo deste nível. Estas características são similares a estudos de casos de sistemas convectivos de mesoescala (SCMs), como o trabalho de Houze (1989), que mostram a relação da formação dos VCMs a partir de SCMs pré-existentes.

Em resumo, na formação do vórtice algumas características marcantes são observadas como: o influxo de ar nos baixos níveis (seta sombreada na figura) a partir da extremidade oeste do sistema que contribui para o transporte de umidade para a média troposfera (Fig. 4a); o predomínio de vorticidade ciclônica na região do VCM até aproximadamente $10 \mathrm{~km}$, onde os fluxos superficiais de calor sensível (H) e latente (LE) são reduzidos quando o VCM está se formando (Fig. 4b) e a atmosfera apresenta umidade relativa (UR) acima de 90\% (próximo da saturação do ar) desde a superfície até $2 \mathrm{~km}$ de altura (Fig. 4c). Acima desse nível
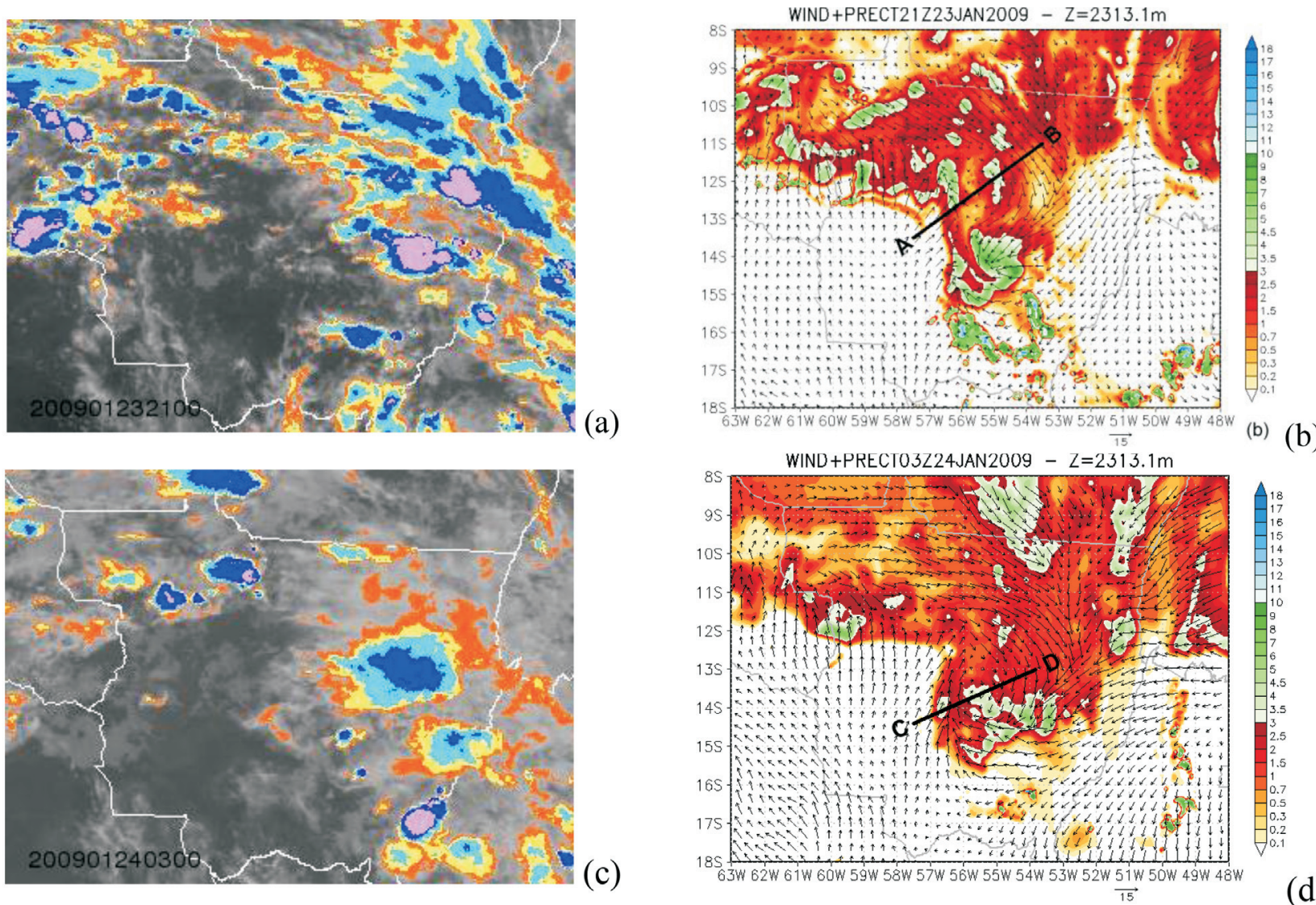

(b)

Figura 2 - Imagem realçada do canal infravermelho do satélite GOES-10 e simulação do modelo BRAMS do campo de vento $\left(\mathrm{m} \cdot \mathrm{s}^{-1}\right)$ na altura de 2313,3 m e precipitação ( $\mathrm{mm}$ ) acumulada horária para $21 \mathrm{Z}$ do dia 23 (a e b), 03Z (c e d), 09Z (e e f) e $12 Z$ ( $\mathrm{g}$ e h) do dia 24 de janeiro de 2009. Os segmentos de reta nos painéis das simulações indicam setores ao longo dos quais serão feitas seções verticais na Figs. 4 e 5 . 


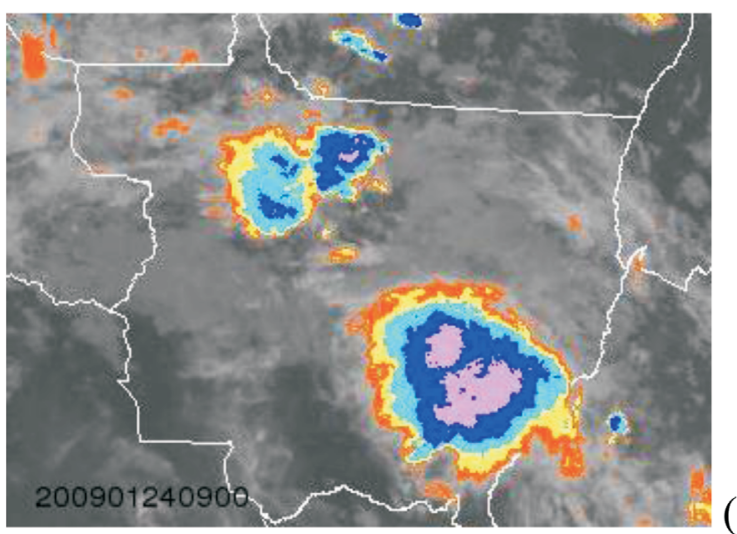

(e)

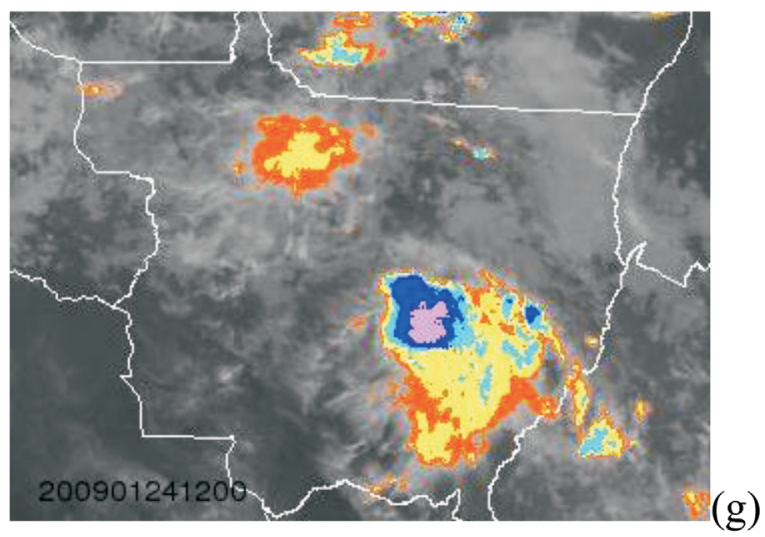

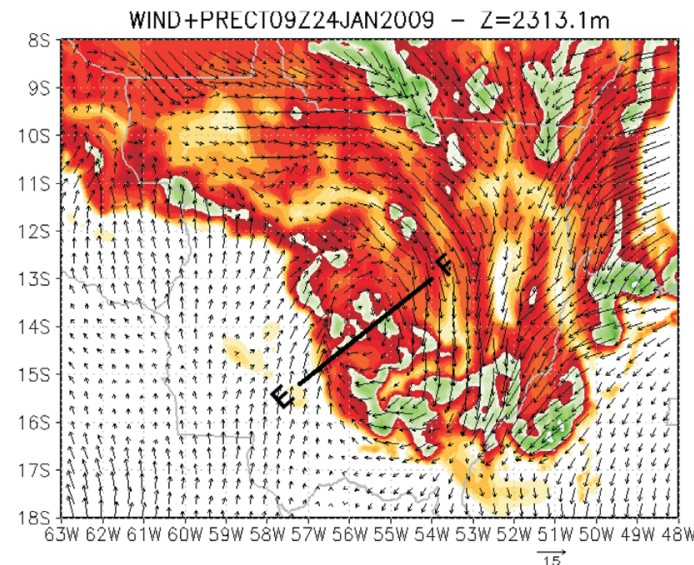

WIND+PRECT12Z24JAN2009 $-Z=2313.1 \mathrm{~m}$

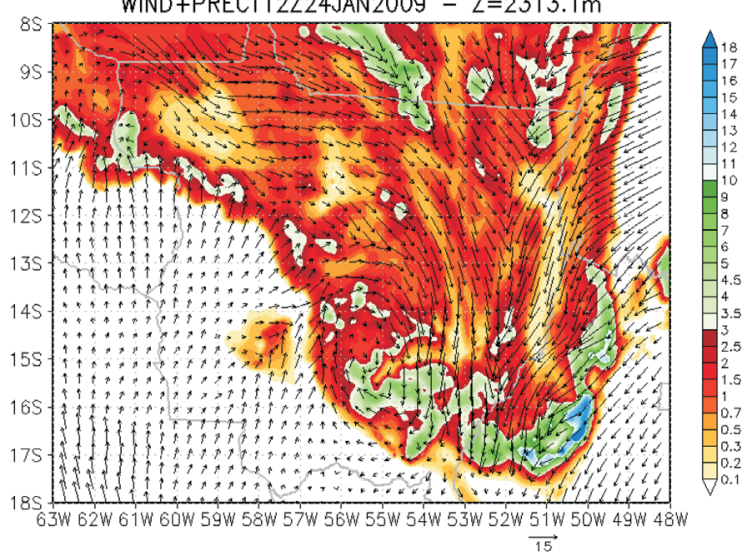

Figura 2 (cont.) - Imagem realçada do canal infravermelho do satélite GOES-10 e simulação do modelo BRAMS do campo de vento (m. $\mathrm{s}^{-1}$ ) na altura de 2313,3 m e precipitação (mm) acumulada horária para $21 \mathrm{Z}$ do dia 23 (a e b), 03Z (c e d), $09 \mathrm{Z}$ (e e f) e $12 \mathrm{Z}$ (g e h) do dia 24 de janeiro de 2009 . Os segmentos de reta nos painéis das simulações indicam setores ao longo dos quais serão feitas seções verticais na Figs. 4 e 5.

até a altitude de $4 \mathrm{~km}$ se observa uma redução significativa de UR associada à convergência de massa e um forte gradiente de temperatura potencial $(\theta)$ na região de formação do vórtice. Acima de $4 \mathrm{~km}$ até a altitude de $10 \mathrm{~km}$ já se verifica divergência do ar quente e úmido ascendente na coluna e, como conseqüência, um aumento de UR até atingir a saturação do ar aproximadamente entre $5.5 \mathrm{~km}$ e $7.5 \mathrm{~km}$ de altitude.

Em relação ao estágio de formação, no horário de máxima intensificação ( $03 Z$ de 24 de janeiro de 2009), o VCM se apresenta bem configurado onde o modelo simula um acumulado maior de precipitação horária ao longo do eixo CD da Fig. 2d, como mostrado na Fig. 5a. Nesta seção vertical se observa movimento ascendente do ar desde a superfície até a altitude de $7 \mathrm{~km}$. A divergência de massa nesse nível contribui com as correntes descendentes de ar na borda oeste $\left(57^{\circ} \mathrm{W}\right)$ e o influxo na baixa troposfera. Nesse horário se verifica também um máximo de circulação ciclônica no centro do VCM $\left(56.7^{\circ} \mathrm{W}\right)$, estendendo-se desde a superfície até $8 \mathrm{~km}$ (Fig. 6b) e convergência de ar úmido e próximo a saturação até o nível de intensidade máxima do vórtice, onde os gradientes de UR e $\theta$ delimitam o contraste de massas do sistema ciclônico. Outra diferença marcante é a redução do fluxo de LE e H em relação ao horário anterior, em função da presença de nebulosidade e precipitação na região.

Neste estágio o mesovórtice já exibe uma estrutura bem definida de um núcleo quente acima e um núcleo frio (piscina fria) abaixo (linha preta da Fig. 3b). Esta piscina fria localizada dentro da camada limite planetária (CLP) é causada principalmente pelas correntes descendentes convectivas úmidas. $\mathrm{O}$ intenso aquecimento em relação ao ambiente, por sua vez, está associado às intensas correntes ascendentes, que acabam provocando uma amplificação no campo de vorticidade relativa (linha preta da Fig. 3a). Essa amplificação será discutida quando da análise dos termos da equação do balanço de vorticidade.

Um perfil vertical no centro do vórtice (Fig. 6) indica que a atmosfera está saturada com até $850 \mathrm{hPa}$ e acima de 4 $\mathrm{km}$ de altura. Entre esses dois níveis se observa uma inversão de subsidência associada à intrusão do ar seco provocado pela divergência de massa (Fig. 5d) logo abaixo da região de máxima intensidade do VCM (2.3 km de altura). Nessa fina camada a atmosfera torna-se estável, mas volta a ficar instável em relação à adiabática úmida acima do nível de máxima vorticidade do vórtice. Outras características 

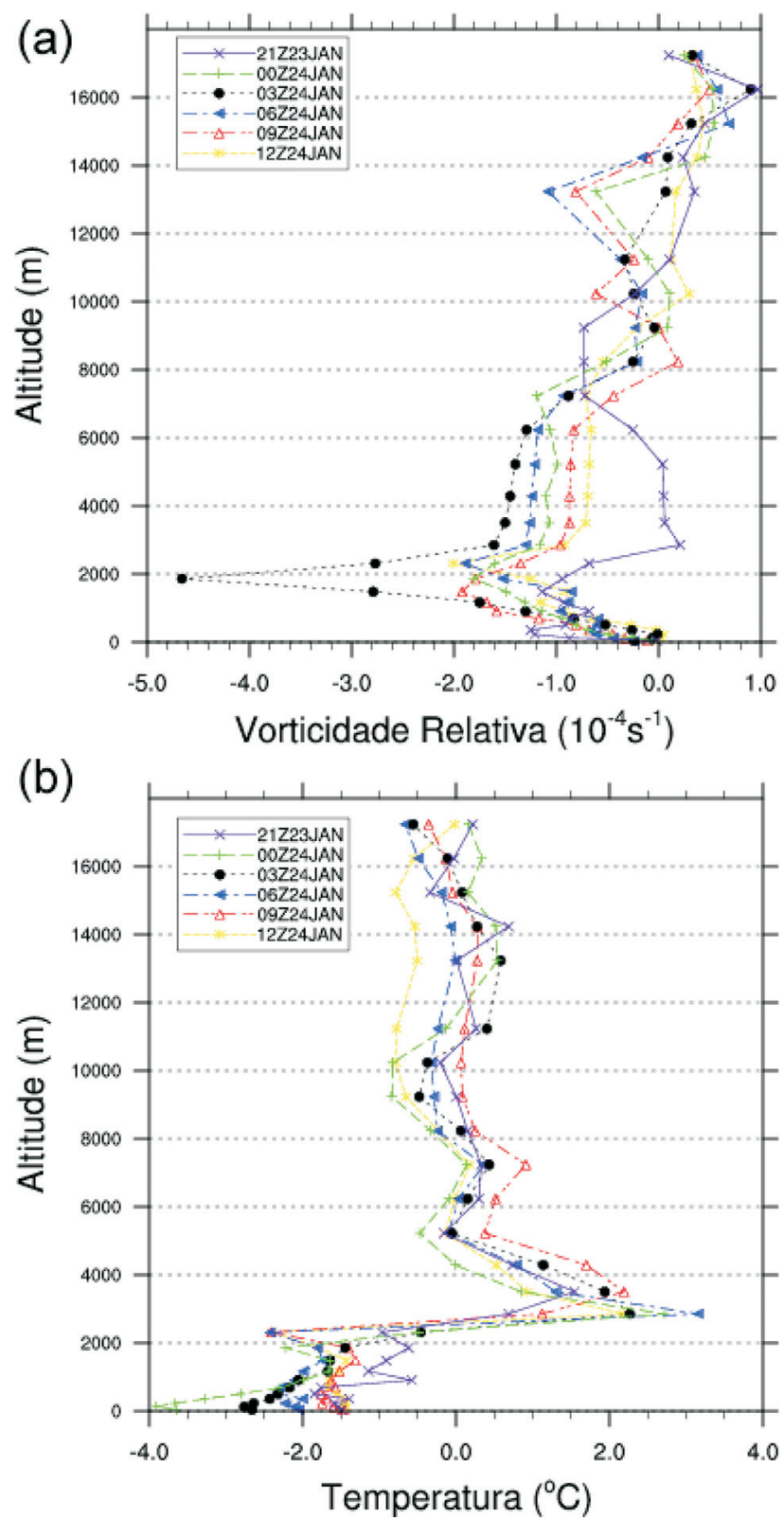

Figura 3 - Perfil vertical de (a) vorticidade relativa $\left(10^{-4} \mathrm{~s}^{-1}\right)$ e (b) anomalia de temperatura $\left({ }^{\circ} \mathrm{C}\right)$ em relação a média zonal no ponto central do mesovórtice as $21 \mathrm{Z}$ de 23 de janeiro, 00Z, 03Z, 06Z, 09Z e 12Z de 24 de janeiro de 2009.

marcantes desse perfil na vertical é o fraco cisalhamento do vento na vertical e o pequeno valor de CAPE (19 J), o que pode retardar o transporte de umidade e energia (calor) em relação às condições médias do ambiente ao redor. Este fator ressalta a importância da presença do vórtice no processo de geração de precipitação embebido na região estratiforme da ZCAS.

Às $09 \mathrm{Z}$ do dia 24 de janeiro, enquanto o sistema convectivo observado na imagem de satélite (Fig 2e) apresenta-se mais intenso, o VCM já apresenta a metade da vorticidade relativa no seu centro, em relação a $6 \mathrm{~h}$ antes. Isso sugere que o sistema já iniciou sua fase de decaimento.
No entanto, a Fig. 7 ainda mostra um padrão da configuração do VCM na vertical semelhante aos horários anteriores. Ainda se observa uma predominância do movimento vertical ascendente associado com a intensa precipitação ao longo do eixo EF da Fig. 2f. No entanto, já não se observa a intrusão de ar frio até próximo da superfície, como no estágio inicial do caso. Com isso, ocorre uma redução da convergência logo abaixo do nível de máxima intensidade do VCM e a divergência de massa ficou confinada entre 8 e $10 \mathrm{~km}$ de altitude (Fig. 7c). O perfil vertical de vorticidade relativa (Fig. $7 b$ ) indica que o VCM aprofundou na coluna atmosférica e a presença de nebulosidade e precipitação mantém os fluxos de $\mathrm{H}$ e LE próximos de zero próximo da região central do vórtice, indicado pelo triângulo preto. No período da manhã e início da tarde verifica-se o enfraquecimento do VCM até o seu desaparecimento.

Para entender a formação desse sistema o balanço médio de vorticidade num raio de $15 \mathrm{~km}$ em torno do centro do VCM é apresentado na Fig. 8. No estágio de formação do vórtice (Fig. 8a), em geral, os termos contribuem para a tendência de vorticidade ciclônica na variação local de $\zeta$ (linha preta) na região da CLP até aproximadamente $1 \mathrm{~km}$ de altitude. Acima desse nível, nesse estágio inicial de formação ainda se observa uma tendência local de vorticidade anticiclônica (positiva) até $8 \mathrm{~km}$ de altura (linha preta). No entanto, abaixo do nível de máxima intensidade do VCM (aproximadamente $2.3 \mathrm{~km}$ ) já se observa uma pequena contribuição negativa dos termos $\mathrm{S}$ (linha marrom - termo solenoidal) e H (linha azul - advecção horizontal de $\zeta$ ), além dos termos V (linha verde - advecção vertical de $\zeta$ ), D (linha vermelha - termo de estiramento pela convergência) e T (linha amarela - torção do componente horizontal da vorticidade) logo acima de $2 \mathrm{~km}$.

Ao longo das próximas seis horas (até as $03 Z$ do dia 24 de janeiro) ocorre um aumento na tendência negativa de $\zeta$ em torno do nível de máxima intensidade do VCM. Pela Fig. 8 b já se verifica uma variação local negativa até $2 \mathrm{~km}$, sendo a contribuição mais significativa dada pelo termo D $\left(-3.8 \times 10^{-8} \mathrm{~s}^{-2}\right)$, seguido pelo termo H $\left(-1.2 \times 10^{-8} \mathrm{~s}^{-2}\right) \operatorname{logo}$ abaixo. Isso mostra que a convergência de massa para a região do VCM, associada à advecção horizontal de $\zeta$ tem um papel importante na intensificação do sistema nos baixos níveis da atmosfera. Acima do nível máximo do VCM até a média troposfera o termo de advecção horizontal contribuiu com vorticidade anticiclônica e nos altos níveis volta a apresentar uma tendência ciclônica significativa (acima de $-3.5 \times 10^{-8} \mathrm{~s}^{-2}$ ) para a variação local de $\zeta$. Nos dois últimos horários apresentados (Figs. $8 \mathrm{c}$ e $8 \mathrm{~d}$ ) para o período da madrugada e inicio da manhã do dia 24 de janeiro, é possível verificar uma redução na contribuição para a intensificação do VCM, o que corrobora os resultados apresentados na Fig. 3a. No entanto é evidente que o termo D de 
estiramento, seguido pelo termo de torção T, são os que mantêm a circulação ciclônica do mesovórtice.

A Fig. 9 mostra uma comparação entre o campo de vento horizontal do modelo BRAMS e da reanálise CFSR do NCEP no nível de máxima intensidade do VCM, e

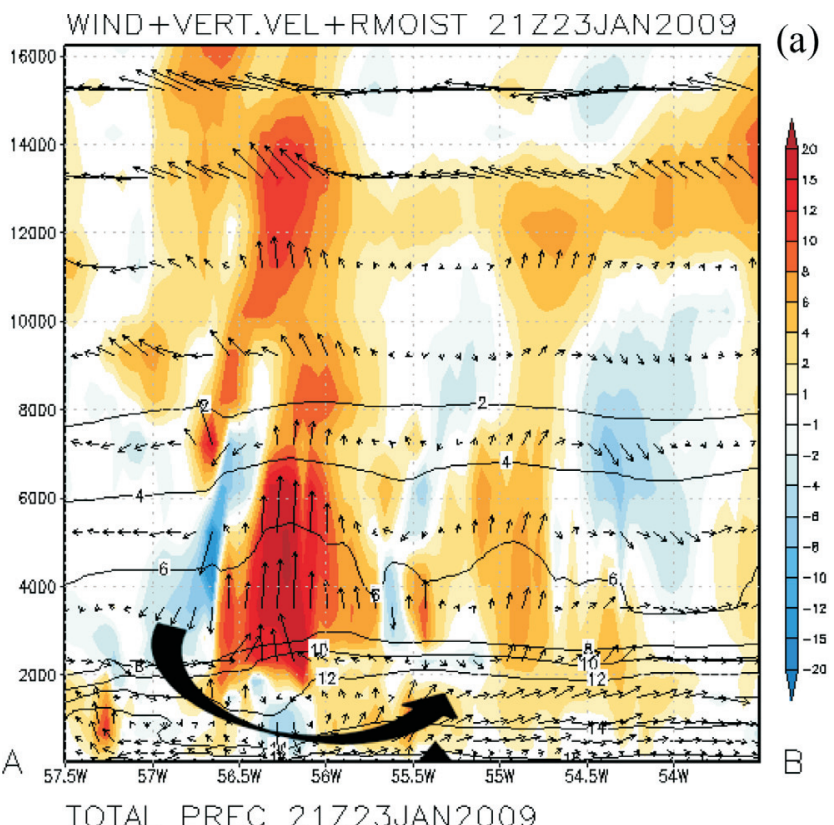

(a)
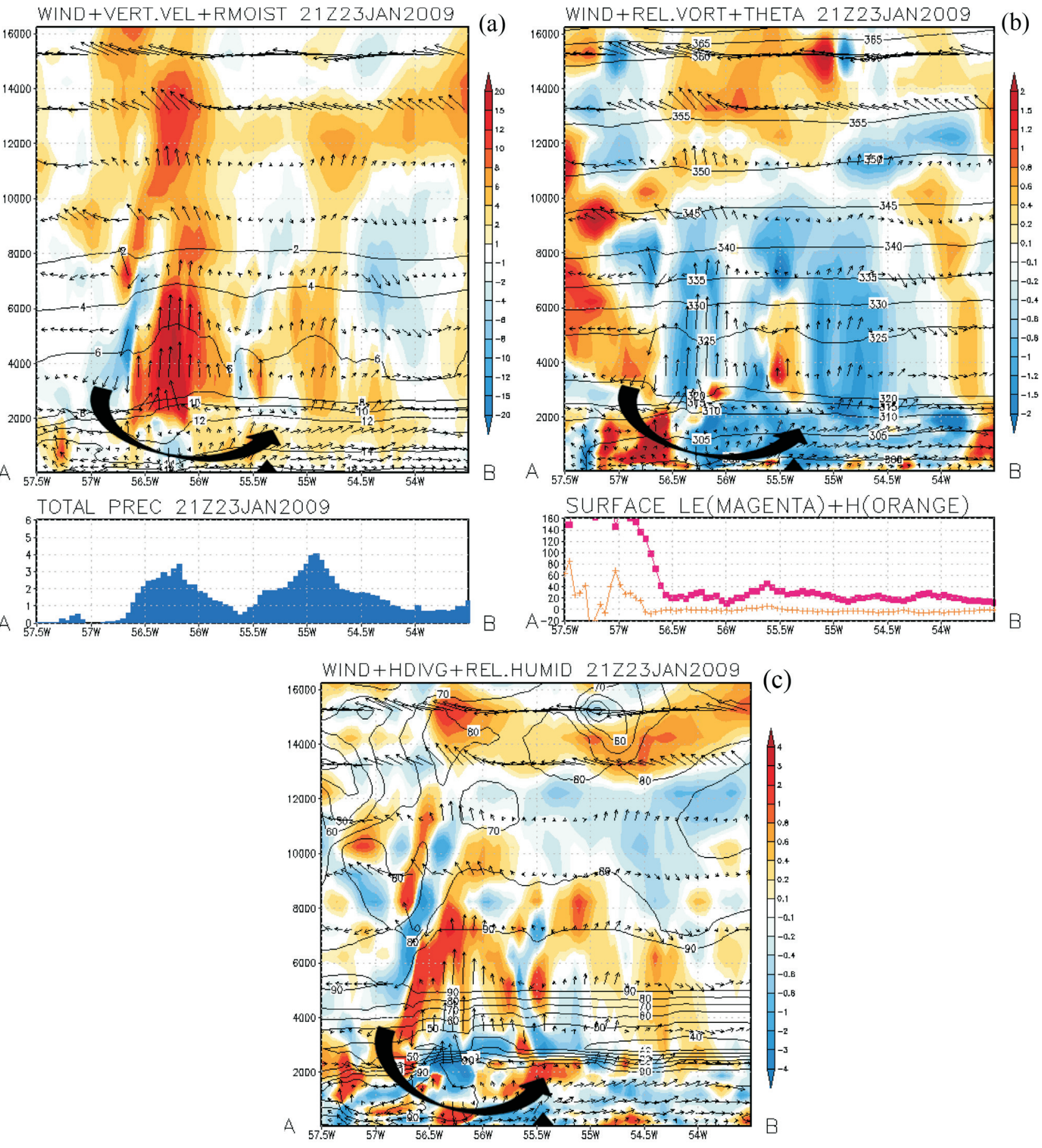

Figura 4 - Seção vertical AB da Fig. 2b para $21 \mathrm{Z}$ de 23 de janeiro de 2009: (a) velocidade vertical (sombreado) (m.s ${ }^{-1}$ ), vetores de vento no plano (x, z), razão de mistura $\left(\mathrm{g}_{\mathrm{kg}} \mathrm{kg}^{-1}\right)$ e precipitação total $(\mathrm{mm})$ acumulada na última hora; (b) vorticidade relativa (sombreado) $\left(10^{-4} \mathrm{~s}^{-1}\right)$, vetores de vento no plano $(\mathrm{x}, \mathrm{z})$, temperatura potencial $(\mathrm{K})$ e fluxos de calor latente (linha rosa) e sensível (linha laranja) $\left(\mathrm{W} / \mathrm{m}^{2}\right)$; (c) divergência de massa (sombreado) $\left(10^{-4} \mathrm{~s}^{-1}\right)$, vetores de vento no plano (x, z) e umidade relativa (\%). Triangulo indica o ponto central do vórtice e a seta sombreada indica o influxo de ar. Componente vertical do vento foi multiplicada por um fator de 10 para melhor visualização dos vetores. 
ção do VCM, comparado com os dados da reanálise CFSR do NCEP (Fig. 9b), gerado com um espaçamento de grade espacial de aproximadamente $50 \mathrm{~km}$ x $50 \mathrm{~km}$. Enquanto o CFSR mostra o centro do sistema localizado em $16.5^{\circ} \mathrm{S} / 51^{\circ} \mathrm{W}$, sobre o estado de Goiás (GO), além de um cavado invertido alongado na direção NW/SE sobre o Estado de MT, o modelo BRAMS mostra o VCM com seu centro localizado em $14^{\circ} \mathrm{S} / 55.5^{\circ} \mathrm{W}$. Em termos de precipitação, o padrão espacial apresentado pela saída do modelo

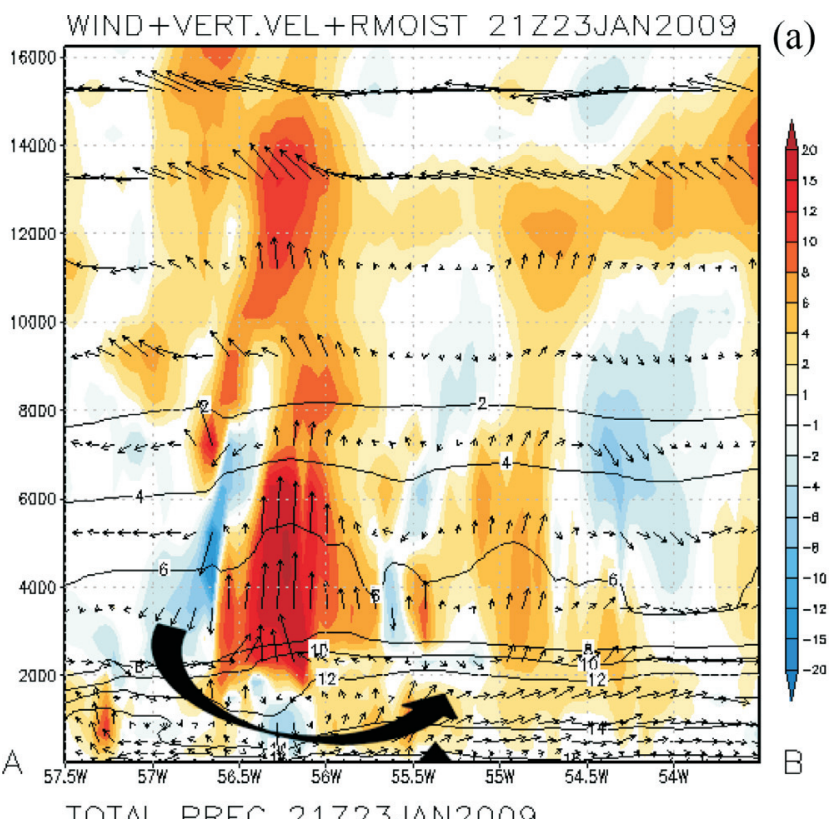

a)
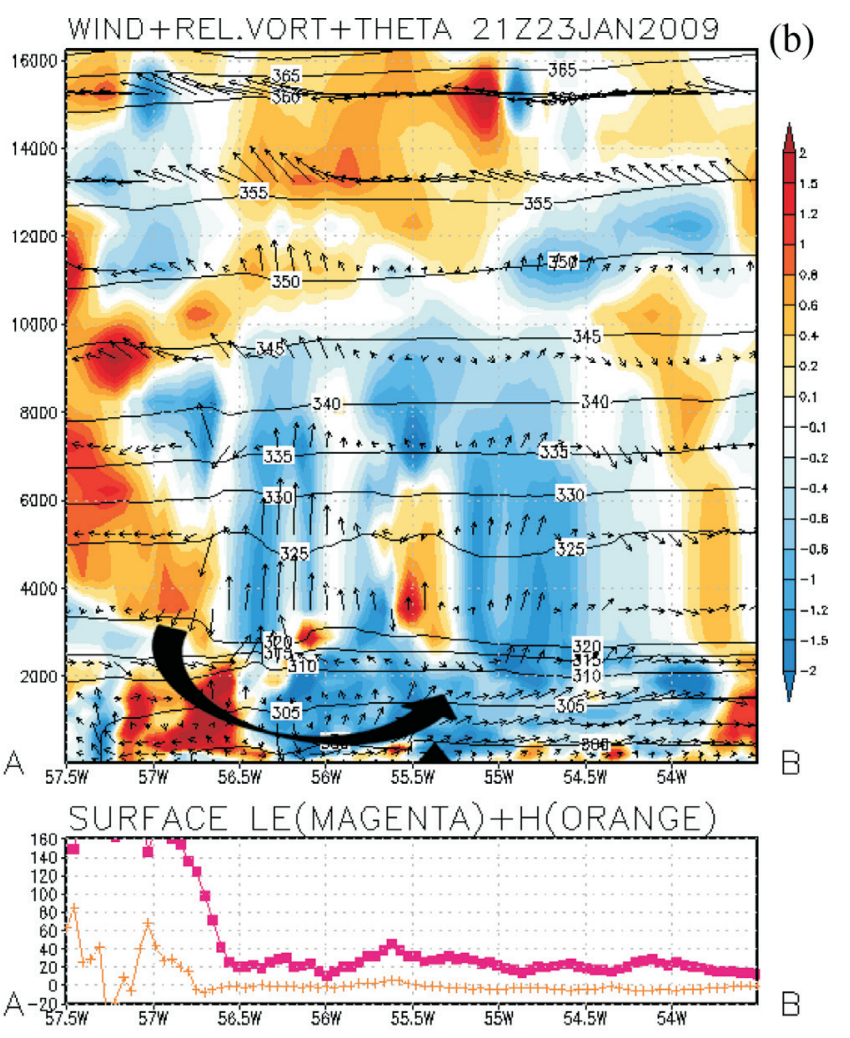

BRAMS é mais consistente com a gerada pelo produto Hidroestimator, que mostra dois núcleos de intensa precipitação localizados na região NW e o segundo no SE de MT. Este segundo máximo (mais intenso) possivelmente está associado com a presença do VCM que provoca precipitação de até $50 \mathrm{~mm} / \mathrm{h}$ no horário selecionado. Com relação à intensidade da precipitação, tanto o BRAMS como o CFSR não simulam os máximos calculados através do produto Hidroestimator. No entanto ressalta-se que o traba-

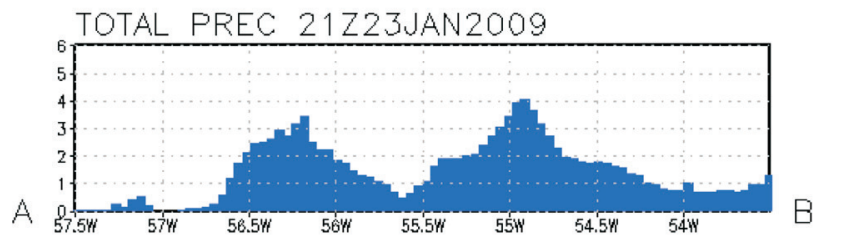

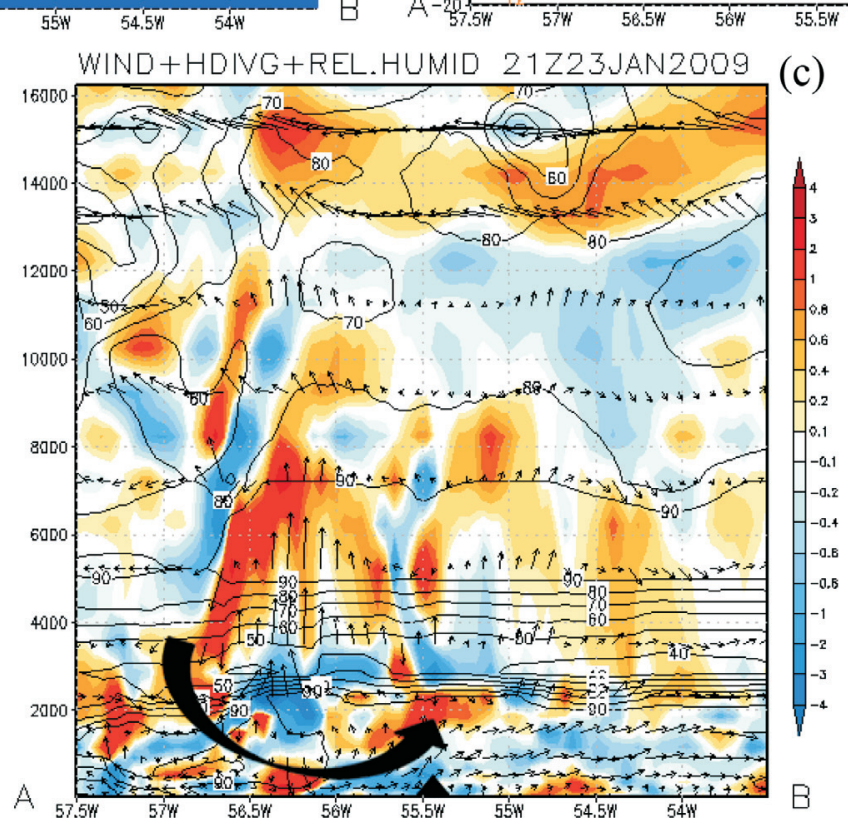

Figura 5 - Como na Fig. 4 para a seção vertical CD da Fig. 2d para 03Z de 24 de janeiro de 2009. 


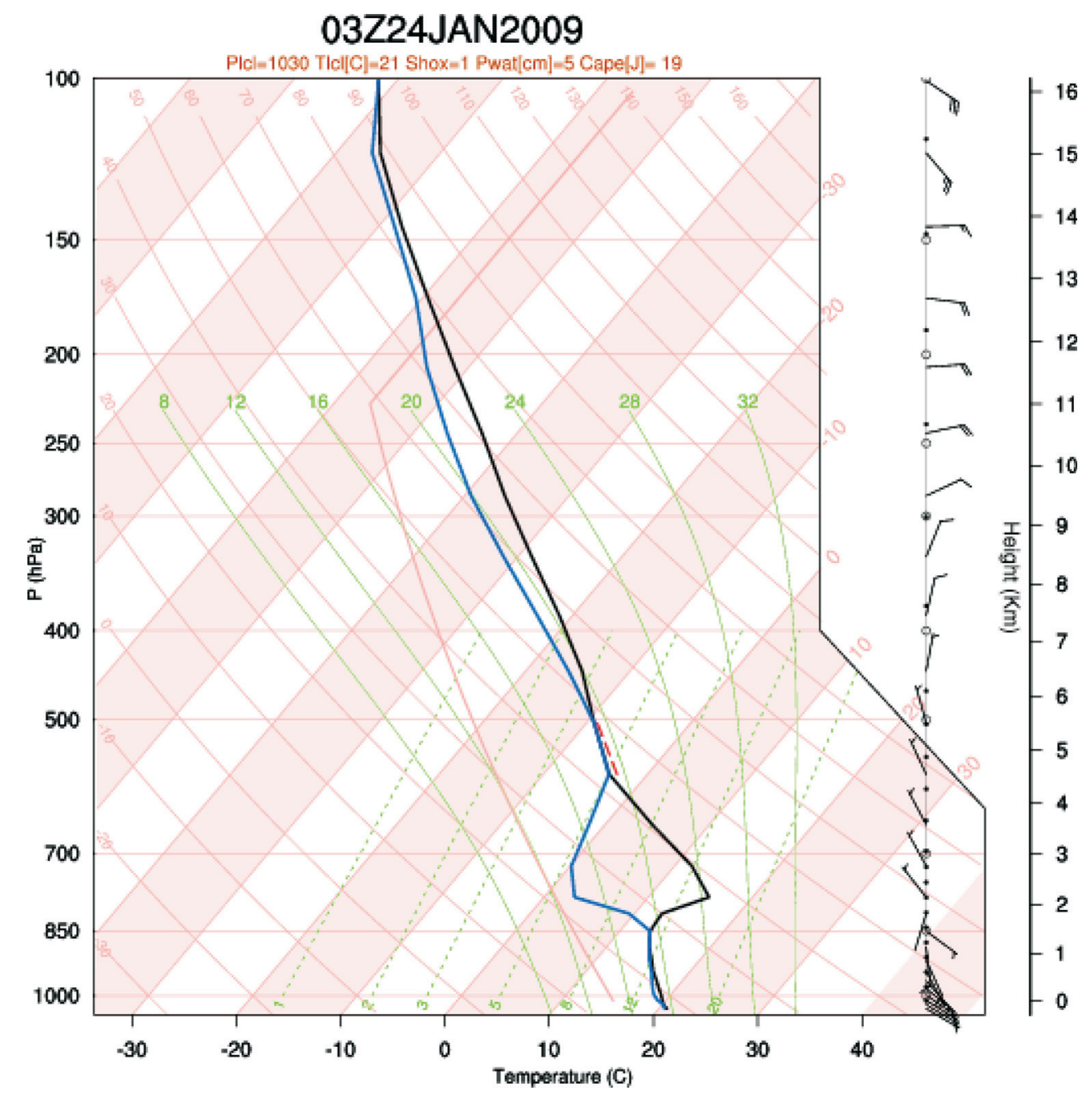

Figura 6 - Diagrama termodinâmico Skew-T/Log-p no ponto central do VCM as 03Z do dia 24 de janeiro de 2009.

lho de Braga et al. (2011), que avaliou o Hidroestimator para três áreas da Região NE do Brasil, mostra que este produto possui valores semelhantes aos pluviométricos em áreas onde ocorrem chuvas convectivas e subestima em regiões onde há presença freqüente de nuvens estratiformes.

\section{Conclusão}

Visando avaliar os mecanismos termodinâmicos que disparam a formação e a atuação dos mesovórtices embebidos na região da ZCAS, realizou-se uma simulação numérica com o modelo BRAMS, durante um período de ZCAS, onde verificou-se a presença de um VCM sobre o Estado de MT entre os dias 22 e 25 de janeiro de 2009. O VCM mostrou características que podem ser consideradas como uma "assinatura" do sistema, apresentando o ciclo de vida inferior a $24 \mathrm{~h}$, escala espacial de aproximadamente $200 \times 200 \mathrm{~km}^{2}$, intensa precipitação, deslocamento no mesmo sentido do escoamento na baixa troposfera, $\zeta$ é da mesma ordem de magnitude de $f\left(10^{-4} \mathrm{~s}^{-1}\right)$, núcleo quente acima do nível de máxima intensidade e um rápido crescimento do centro de vorticidade ciclônica principalmente nos baixos níveis.

Foram evidenciadas algumas características típicas dos vórtices convectivos de mesoescala detectadas por diversos pesquisadores (Chen e Frank, 1993; James e Johnson, 2010). Sua estrutura térmica apresenta uma piscina fria na CLP abaixo do nível vertical de máxima vorticidade ciclônica devido à evaporação e ao derretimento da precipitação e uma taxa de aquecimento de até $3{ }^{\circ} \mathrm{C}$, devido à condensação, acima do nível de $\zeta$ máximo no período da noite e madrugada dentro da região estratiforme do VCM. Com relação a sua estrutura termodinâmica, que apresentou um padrão semelhante nos dois casos, o ambiente encontra-se saturado em quase toda troposfera, exceto por uma inversão de subsidência associada à intrusão do ar seco provocado pela divergência de massa logo abaixo da região de máxima intensidade do VCM. Esse perfil apresenta também um fraco cisalhamento do vento na vertical e um valor de CAPE pequeno. Estes fatores combinados ressaltam a importância da presença do vórtice no processo de 
geração de precipitação embebido na região estratiforme da ZCAS.

Visando compreender a formação e o desenvolvimento deste VCM formado na região continental, foi calculado o balanço de vorticidade em torno da região central do sistema. No estágio inicial, os termos do balanço contribuem com a tendência de vorticidade ciclônica na região da CLP até aproximadamente $1 \mathrm{~km}$ de altitude. Sugere-se que os efeitos de superfície (calor latente e sensível) associados
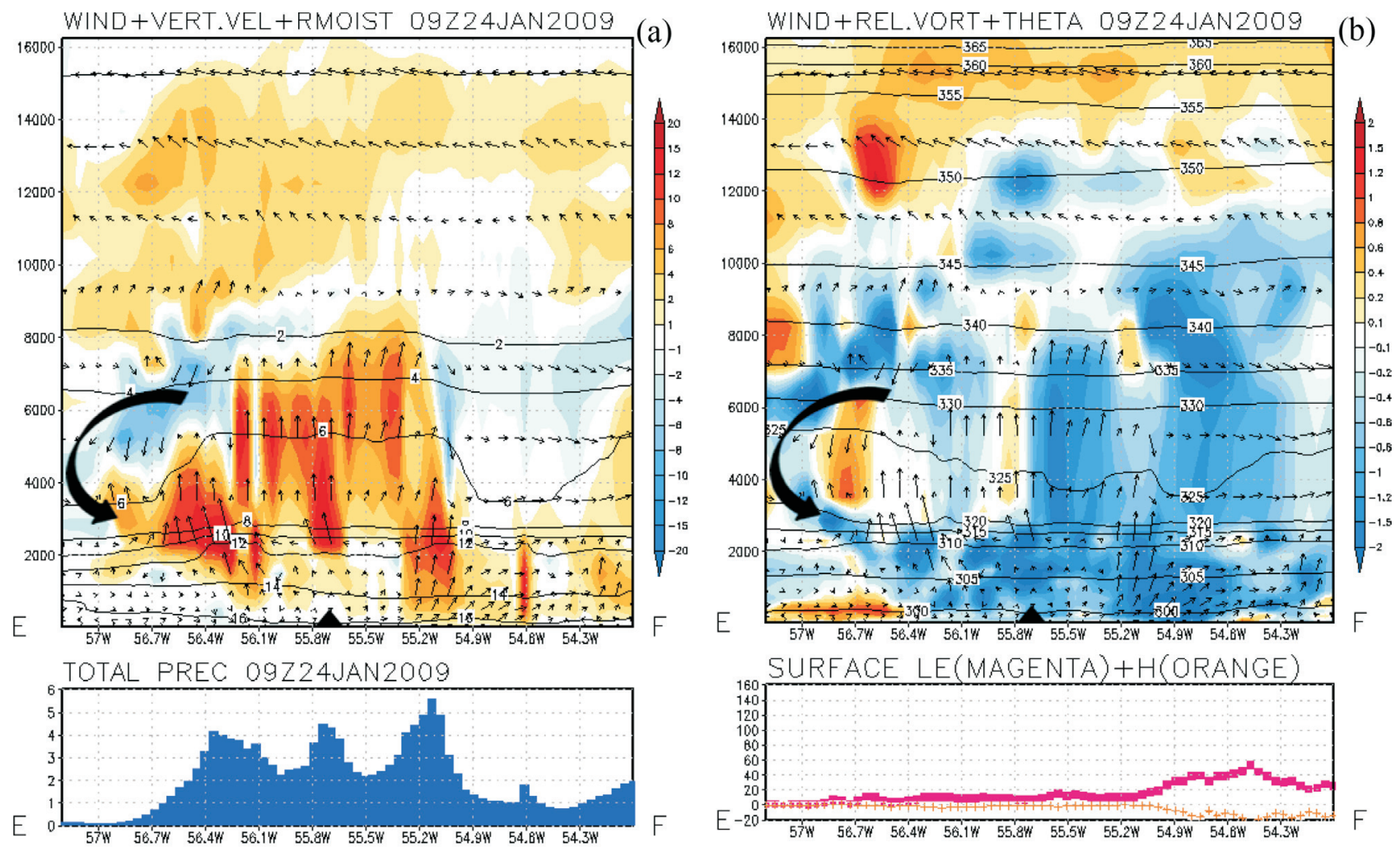

Figura 7 - Como na Fig. 4 para a seção vertical CD da Fig. 2d para 09Z de 24 de janeiro de 2009. 
contribuição mais significativa dada pelo termo D seguido pelo termo $\mathrm{H}$ logo abaixo. Isso mostra que este rápido crescimento é devido à intensa convergência de massa, associada à advecção horizontal de $\zeta$, que contribuem significativamente para o desenvolvimento do VCM. No estágio final ocorre uma redução na contribuição dos termos do balanço para a intensificação do mesovórtice. No entanto

(a)

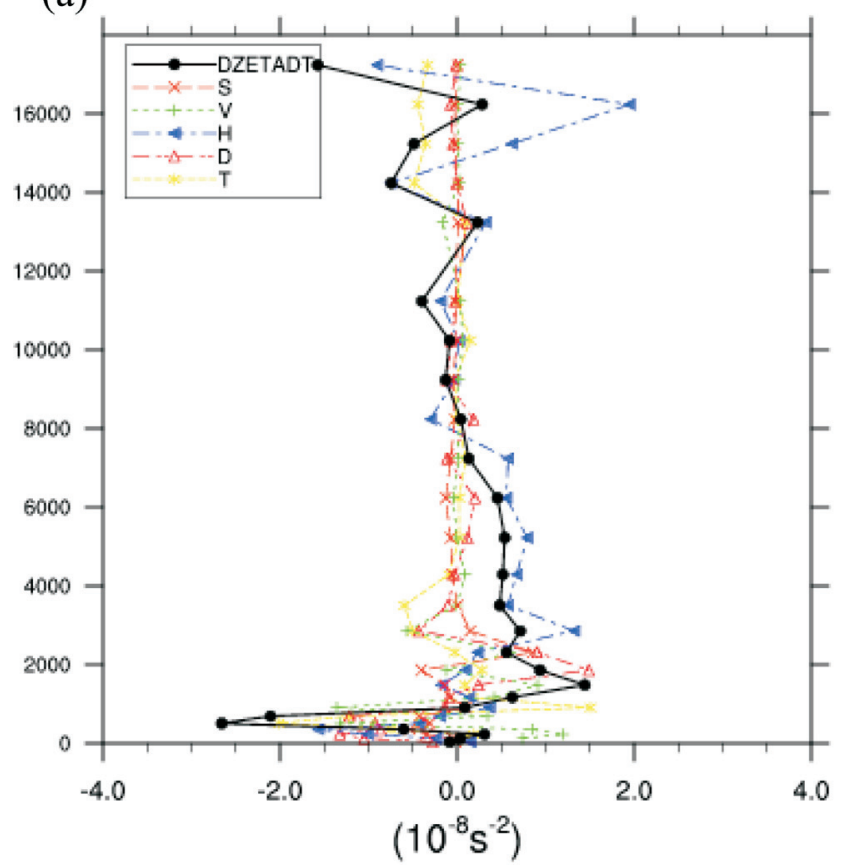

(c)

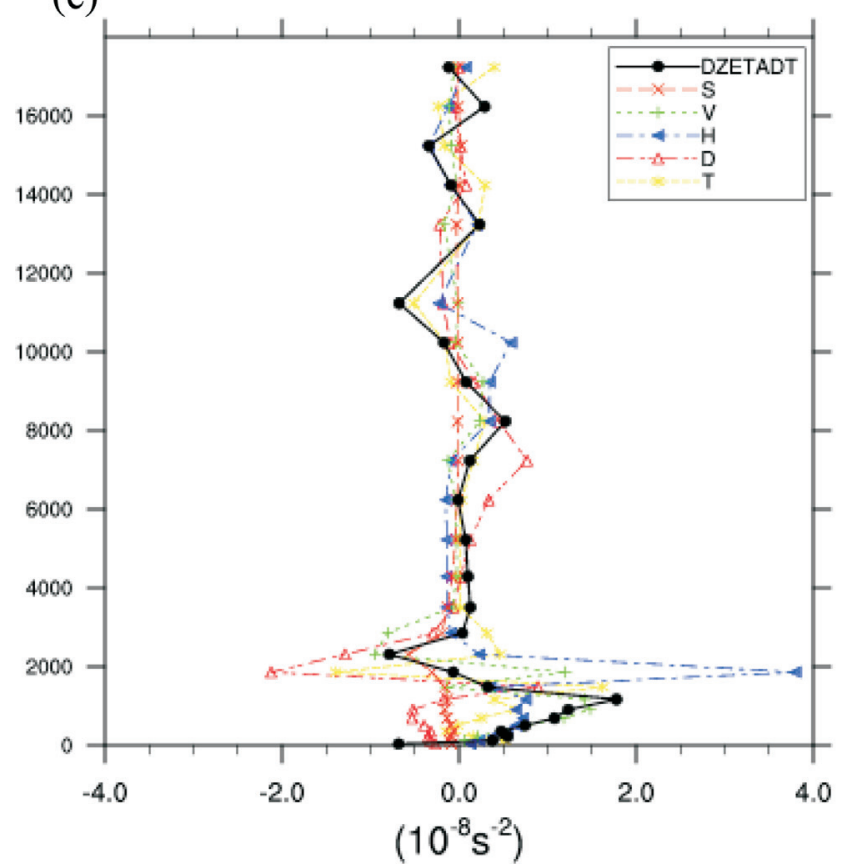

os termo de estiramento e de torção T mantêm a circulação ciclônica deste sistema de mesoescala até sua dissipação.

Em uma etapa posterior foi realizada a comparação entre o campo de vento horizontal do modelo BRAMS e da reanálise CFSR do NCEP no nível de máxima intensidade do VCM e da precipitação horária acumulada entre estes dois modelos e o produto Hidroestimador. Apesar da defi-

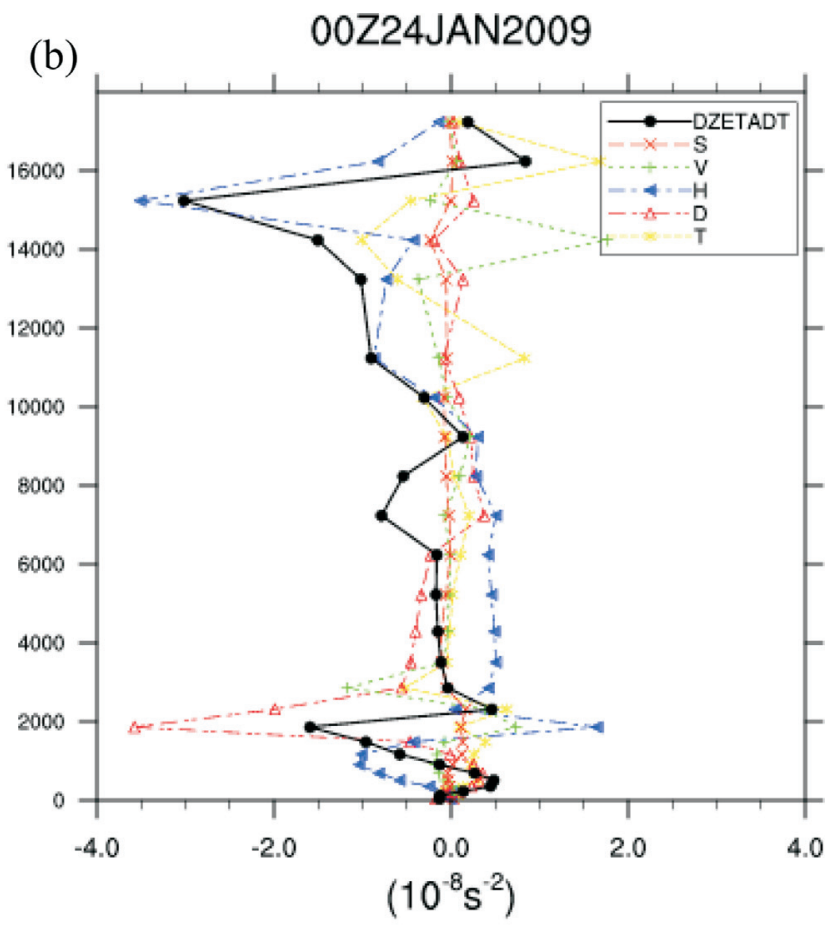

(d) 09Z24JAN2009

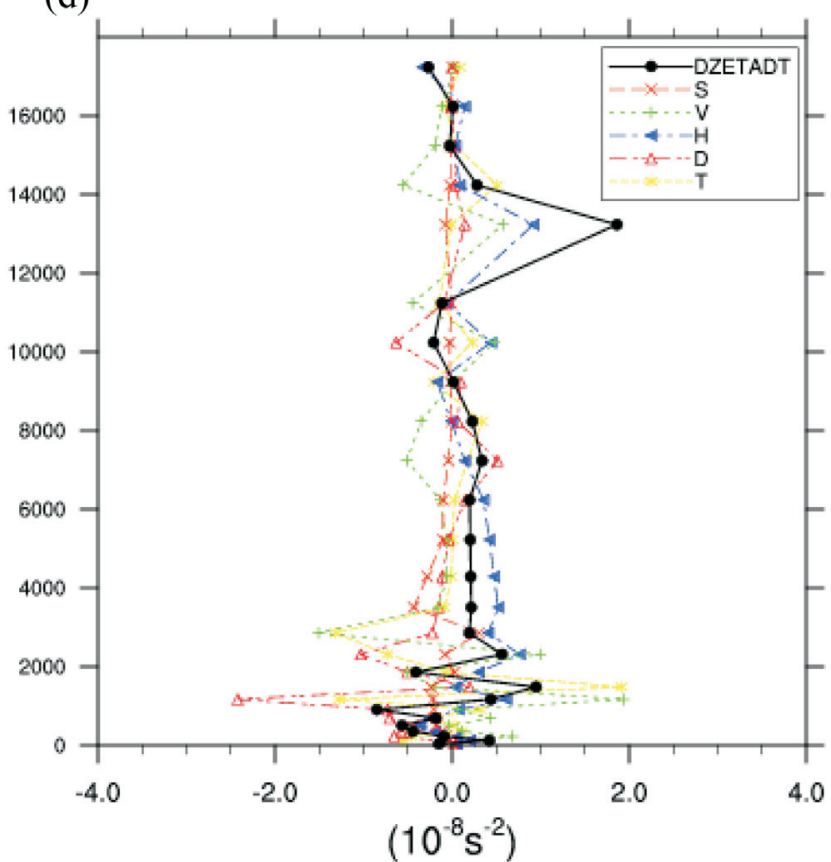

Figura 8 - Perfil vertical da tendência de vorticidade relativa média, no raio de $15 \mathrm{~km}$ em torno do centro do VCM, para cada termo da equação (1) as $21 \mathrm{Z}$ do dia 23 de janeiro (a), $00 \mathrm{Z}$ (b), $03 \mathrm{Z}$ (c) e $09 \mathrm{Z}$ (d) do dia 24 de janeiro de 2009. 

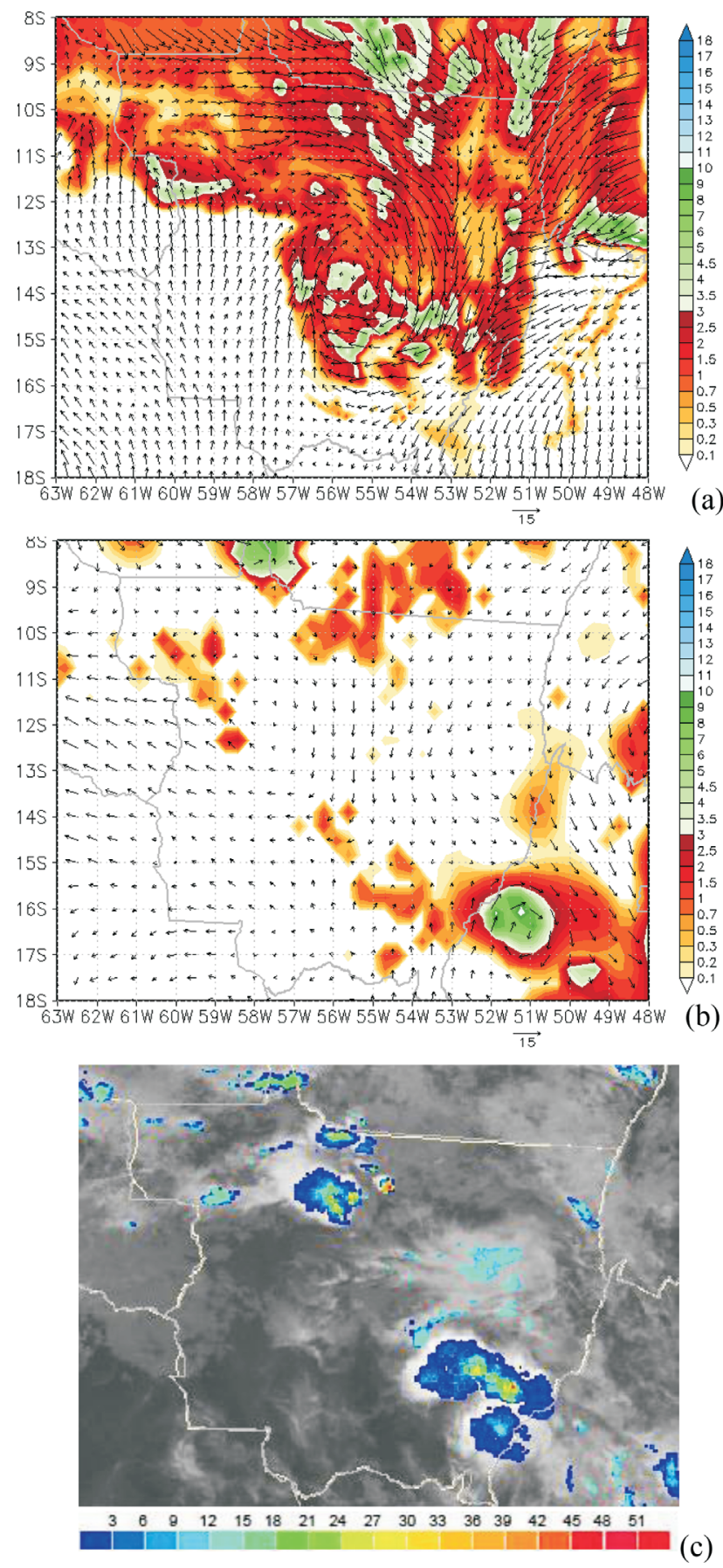

Figura 9 - Comparação entre os campos de vento $\left(m \cdot s^{-1}\right)$ e precipitação (mm) acumulada horária do modelo BRAMS na altitude de $2313 \mathrm{~m}$ (a), da reanálise CFSR do NCEP em $800 \mathrm{hPa}$ (b) e do produto HIDROESTIMADOR (c) para as 06Z do dia 24 de janeiro de 2009.

ciência de informações meteorológicas nas regiões analisadas principalmente em superfície para executar o processo de assimilação e gerar as condições inicias do modelo atmosférico, sugere-se que o modelo BRAMS, com uma alta resolução espacial e temporal, melhora a representação do VCM, comparado com os dados da reanálise CFSR do NCEP.

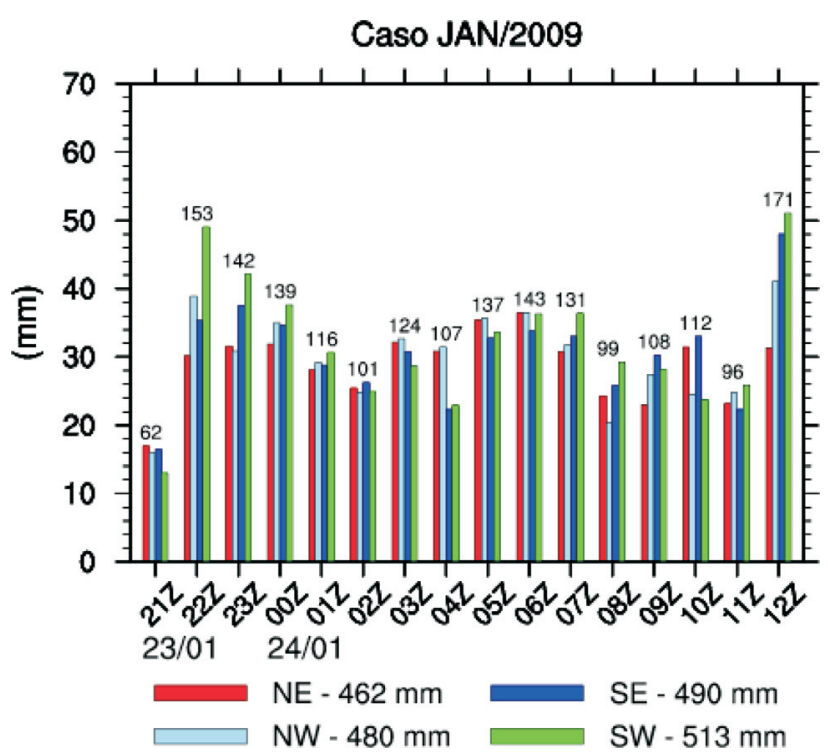

Figura 10 - Série temporal da precipitação horária ( $\mathrm{mm})$ acumulada nos retângulos de $15 \mathrm{~km}^{2}$ na regiões NE (vermelho), SE (azul), SW (verde) e NW (azul claro) do centro dos VCM analisados em janeiro de 2009 (a) e fevereiro de 2008 (b).

É de senso comum que a ZCAS, através da persistência da precipitação em determinadas áreas, afeta drasticamente as regiões atingidas provocando sérios danos sócio-econômicos. A Fig. 10 reflete essa situação através do gráfico da série temporal da precipitação acumulada (mm) em torno da região do centro do VCM . Fica evidente que o mesovórtice está associado com intensa precipitação durante todo período de atuação. Outra característica importante é de que estes índices pluviométricos são proporcionalmente bem distribuídos entre as quatro regiões subdivididas em torno do centro do centro do VCM. As regiões para onde os VCMs se deslocam (região sul neste caso de janeiro de 2009) recebem acumulados pluviométricos ligeiramente mais elevados que as demais regiões. Em relação ao total acumulado horário em torno dos vórtices (legenda acima das barras), verifica-se uma distribuição homogênea da precipitação durante os estágios de vida do VCM. Esse fato ressalta a importância da análise deste sistema em ambientes operacionais durante todo seu ciclo de vida.

\section{Agradecimentos}

Os autores agradecem o suporte financeiro recebido da Coordenação de Aperfeiçoamento de Pessoal de Nível Superior pela Coordenação de Programas de Qualificação de Quadros Docentes (PICDTec/CAPES) pela bolsa de estudos. 


\section{Referências}

Bartels, D.L.; MADDOX, A. Midlevel cyclonic vortices generated by mesoscale convective systems. Monthly Weather Review, v. 119, p. 104-118, 1991.

Bosart, L.F.; Sanders, F. The Johnstown flood of July 1977: A long-lived convective system. Journal of the Atmospheric Sciences, v. 38, p. 1616-1642, 1981.

BRAGA, R.C.; LIMA, W.F.A.; VENDRASCO, E.P.; VILA, D. Análise do Algoritmo Hidroestimador na Climatologia de Chuvas na Região Nordeste do Brasil. IV Simpósio Internacional de Climatologia, João Pessoa, PB. 2011. Disponível em http://urlib.net/8JMKD3MGP7W/3APNKNP, acesso em 13/1/2012.

Brandes, E.A.; ZIEGLER, C.L. Mesoscale downdraft influences on vertical vorticity in a mature mesoscale convective system. Monthly Weather Review, v. 121, p. 1337-1353, 1993.

Chen, S.S.; Frank, W.M. A numerical study of the genesis of extratropical convective mesovortices. Part I: Evolution and dynamics. Journal of the Atmospheric Sciences, v. 50, p. 2401-2426, 1993.

CHEN, S.J; KUO, Y.H.; WANG, W.; TAO, Z.Y.; CUI, B. Modeling Case Study of Heavy Rainstorms along the Mei-Yu Front. Monthly Weather Review, v. 126, p. 2330-2351, 1998.

CHEN, S.J.; WANG, W.; LAU, K.H. ZHANG, Q.H.; CHUNG, Y.S. Mesoscale convective systems along the Meiyu front in a numerical model. Meteorology and Atmospheric Physics, v. 75, p. 149-160, 2000.

FERREIRA, N.J.; SANCHES, M.; SILVA DIAS, M.A.F. Composição da Zona de Convergência do Atlântico Sul em Períodos de El Niño e La Niña. Revista Brasileira de Meteorologia, v. 19, n. 1, p. 89-98, 2004.

FREITAS, S.R.; LONGO, K.M.; SILVA DIAS, M.F.A.; CHATFIELD, R.; SILVA DIAS, P.L. et al. The Coupled Aerosol and Tracer Transport model to the Brazilian developments on the Regional Atmospheric Modeling System (CATT-BRAMS). Part 1: Model description and evaluation, Atmospheric Chemistry and Physics, v. 7, p. 8525-8569, 2007.

GRIMM, A.M. Interannual climate variability in South America: impacts on seasonal precipitation, extreme events and possible effects of climate change. Stochastic Environmental Research and Risk Assessment. v. 25, n. 4, p. 537-554, 2011.

Houze, R.A.Jr.: Structure and dynamics of a tropical squall line system. Monthly Weather Review, v. 105, p. 1541-1567, 1977.

Houze Jr., R.A; Rutledge, S.A.; Biggerstaff, M.I.; Smull, B.F. Interpretation of Doppler weather radar displays of midlatitude mesoscale convective systems. Bulletin of the American Meteorological Society, v. 70, p. 608-619, 1989.
James, E.P.; Johnson, R.H. Patterns of precipitation and mesolow evolution in midlatitude mesoscale convective vortices. Monthly Weather Review, v. 138, p. 909-931, 2010.

Johnson, R.H.; Bartels, D.L. Circulations associated with a mature-to-decaying midlatitude mesoscale convective system. Part II: Upper-level features. Monthly Weather Review, v. 120, p. 1301-1320, 1992.

Johnston, E.C. Meso-scale vorticity centers induced by mesoscale convective complexes. M. S. thesis, University of Wisconsin-Madison, 54 pp, 1982.

MELLOR, G.L.; YAMADA, T. Development of a turbulence closure model for geophysics fluid problems . Reviews of Geophysics and Space Physics, v. 20, p. 851-875, 1982.

Ninomiya, K. Similarity and difference between the South Atlantic Convergence Zone and the Baiu Frontal Zone simulated by an AGCM. Journal of the Meteorological Society of Japan, v. 85, n. 3, p. 277-299, 2007.

NÓBILE TOMAZIELLO, A.C. Influências da temperatura da superfície do mar e da umidade do solo na precipitação associada à Zona de Convergência do Atlântico Sul. Mestrado em Meteorologia - Instituto de Astronomia, Geofísica e Ciências Atmosféricas, Universidade de São Paulo, 166 p, SãO PAULO, 2010.

QUADRO, M.F.L. Estudo de Vórtices Ciclônicos de Mesoescala associados à Zona de Convergência do Atlântico Sul. Tese de Doutorado em Meteorologia, Instituto de Astronomia, Geofísica e Ciências Atmosféricas, Universidade de São Paulo, 141 pp, São Paulo, 2012.

SAHA, S.; Moorthi, S.; Pan, H.L.; Wu, X.; Wang, J. et. al. The NCEP Climate Forecast System Reanalysis. Bulletin of the American Meteorological Society, v. 91, n. 8, p. 10151057, 2010.

SCOFIELD, R.A. Comments on "A quantitative assessment of the NESDIS Auto-Estimador." Weather Forecasting, v. 16, n. 277-278, 2001.

TOON, O.B.; McKAY, C.P.; ACKERMAN, T.P., SANTHANAM, K. Rapid Calculation of Radiative Heating Rates and Photodissociation Rates in Inhomogeneous Multiple Scattering Atmospheres, Journal of Geophysical Research, v. 94, p. 16287-16301, 1989.

VICENTE, G.A.; SCOFIELD, R.A.; MENZEL, W.P. The operational GOES infrared rainfall estimation technique. Bulletin of the American Meteorological Society, v. 79, n. 9, p. $1883-1898,1998$.

WALKO, R.L.; COTTON, W.R.; MEYERS, M.P.; HARRINGTON, J.Y. New RAMS cloud physics parameterization. Part I: The single-moment scheme. Atmospheric Research, v. 38, p. 3-39, 1995.

Zhang; D.L.; Fritsch, J.M. Numerical simulation of the meso-b scale structure and evolution of the 1977 Johnstown flood. Part II: Inertially stable warm-core vortex and the mesoscale convective complex. Journal of the Atmospheric Sciences, v. 44, p. 2593-2612, 1987.

All the contents of this journal, except where otherwise noted, is licensed under a Creative Commons Attribution License CC-BY. 